\title{
Reductive Radical Cascades Triggered by Alkoxyl Radicals in the $\beta$-Cyclodextrin Framework
}

\author{
Elisa I. Leoń,Angeles Martín,*_ IneśPérez-Martín, and Ernesto Suárez*
}

Síntesis de Productos Naturales, Instituto de Productos Naturales y Agrobiología del CSIC, Carretera de la Esperanza 3, 38206 La

Laguna, Tenerife, Spain

\section{${ }^{*}$ s Supporting Information}

ABSTRACT: The generation and fate of $2^{\mathrm{I}-\mathrm{VII}}, 3^{\mathrm{I}-\mathrm{VII}}, 6^{\mathrm{II}-\mathrm{VII}}-\mathrm{icosa}-\mathrm{O}-$ methyl $-\beta$ cyclomaltoheptaos- $6{ }^{\mathrm{I}}-\mathrm{O}$-yl radical under reductive conditions is described. Two radical cascade reactions are involved: the main one is triggered by a 1,8-HAT of the hydrogen at $5^{\mathrm{VII}} \mathrm{C}$. The radical can reach the anomeric hydrogen at $1^{\mathrm{V}} \mathrm{C}$ three sugar units ahead using a six-step sequence. The different hydrogen donor ability of the group 14 hydrides permits one to selectively stop the cascade at $5^{\mathrm{VII}} \mathrm{C}, 2^{\mathrm{VI}} \mathrm{C}$, and $4^{\mathrm{VI}} \mathrm{C}$ to obtain $\beta$-CD with a $\beta$-L-Idop unit, acyclic hepta-, and hexa-saccharide structures, respectively.

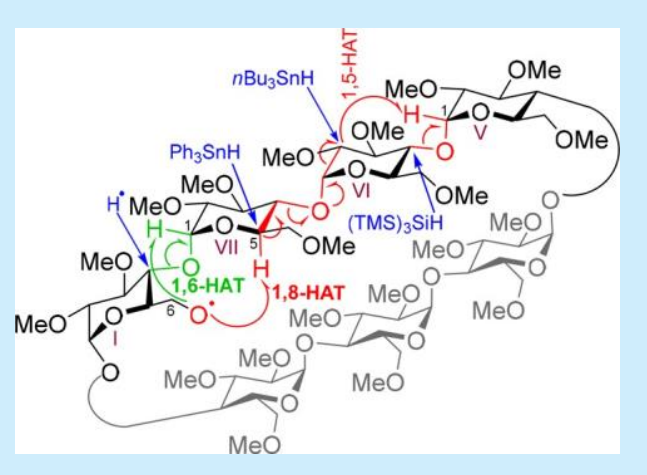

$\mathrm{R}$ adical cascade reactions have attracted a great deal of attention, because of the high degree of efficiency and selectivity that can be achieved in the construction of complex organic molecules. ${ }^{1}$ In practically all of these processes, double and/or triple bonds are involved, the 5-exo and 6-endo radical cyclizations being the most representative steps of the sequence. The use of alkoxyl radicals in these cascade reactions has scarcely been reported. Only a few examples of the preparations of carbocycles and heterocycles using intramolecular cyclizations initiated by alkoxyl radicals via 1,5hydrogen atom transfer (HAT) have been published. ${ }^{2}$ The $\beta$ fragmentation of alkoxyl radicals for the initio or propagation of a cascade reaction has not been widely used either. ${ }^{\underline{3}}$

In previous papers, ${ }^{4}$ we have reported on an intramolecular 1,8-HAT reaction between the two pyranose units in Hexp$(1 \rightarrow 4)$-Hex $p$ disaccharide systems for remote $\mathrm{C}-\mathrm{H}$ functionalization initiated by alkoxyl radicals. .5 For example, the $\alpha$-DGlc $p$ - $(1 \rightarrow 4)-\beta-D-G l c p-6^{\mathrm{I}}-\mathrm{O}$-yl (I) radical, prepared from maltose, abstracts regioselectively the hydrogen at $5^{\mathrm{II}} \mathrm{C}$ hydrogen (II) (see Scheme 1). A possible alternative pathway, the 1,6-HAT of the $1^{\mathrm{II}} \mathrm{C}$ hydrogen was not observed. Under reductive conditions a new $\beta$-L-Idop-( $1 \rightarrow 4)-\beta-\mathrm{D}-\mathrm{Gl} p$ disaccharide (III), derived from the attack of the hydride at $5^{\mathrm{II}} \mathrm{C}$ with inversion of configuration, is formed. Under oxidative conditions, notwithstanding, the reaction proceeds in a completely different way, by a radical-polar crossover mechanism and a compound possessing a rare 1,3,5-trioxocane ring (IV), with retention of configuration at $5^{\mathrm{II}} \mathrm{C}$, is obtained instead.

We have also studied this 1,8-HAT reaction on cyclic oligosaccharides, cyclodextrins (CDs), although only using the oxidative procedure to generate the alkoxyl radical. ${ }^{-}$The application of a reductive protocol to CDs would allow us to

Scheme 1. Synthesis of $\beta$-L-Idop-( $1 \rightarrow 4)-\beta$-DGlcp

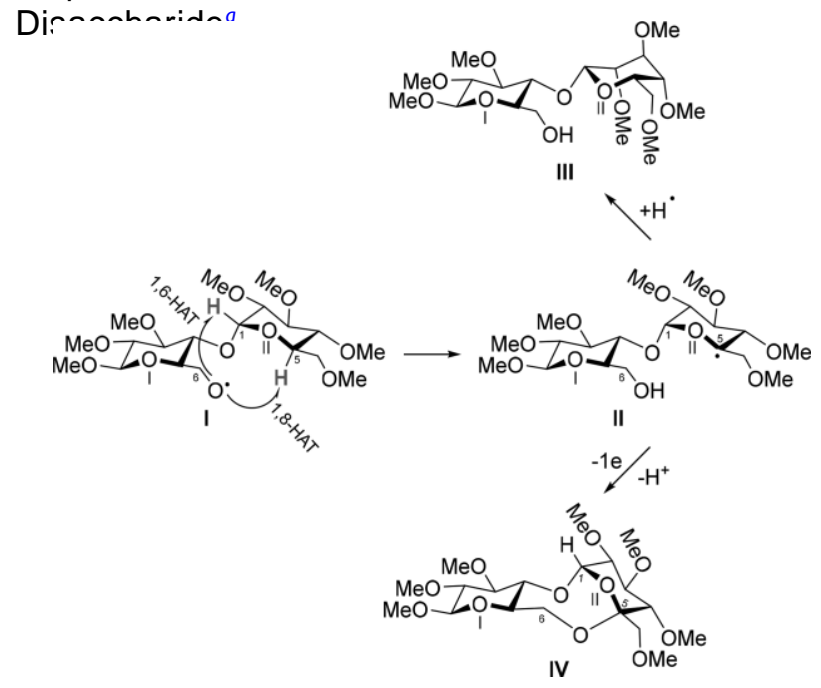

${ }^{a} \mathrm{HAT}=$ hydrogen atom transfer.

change an $\alpha$-D-Glc $p$ unit into $\beta$-L-Idop in a single-step. To our knowledge, such a $C D$ with a $\beta$-L-Idop unit in its structure has never been prepared, although some CDs containing L-residues are known. ${ }^{7}$ This would entail a modification of the cavity by altering the conformation of this unit from ${ }^{4} C_{1}$ to ${ }^{1} C_{4}$, which may consequently influence the inclusion complexation behavior of the CD. ${ }^{-}$Herein, we disclose the generation and

Received: April 25, 2018

Published: May 16, 2018 


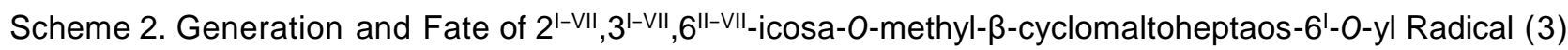
under Reductive Conditions ${ }^{\underline{a}}$

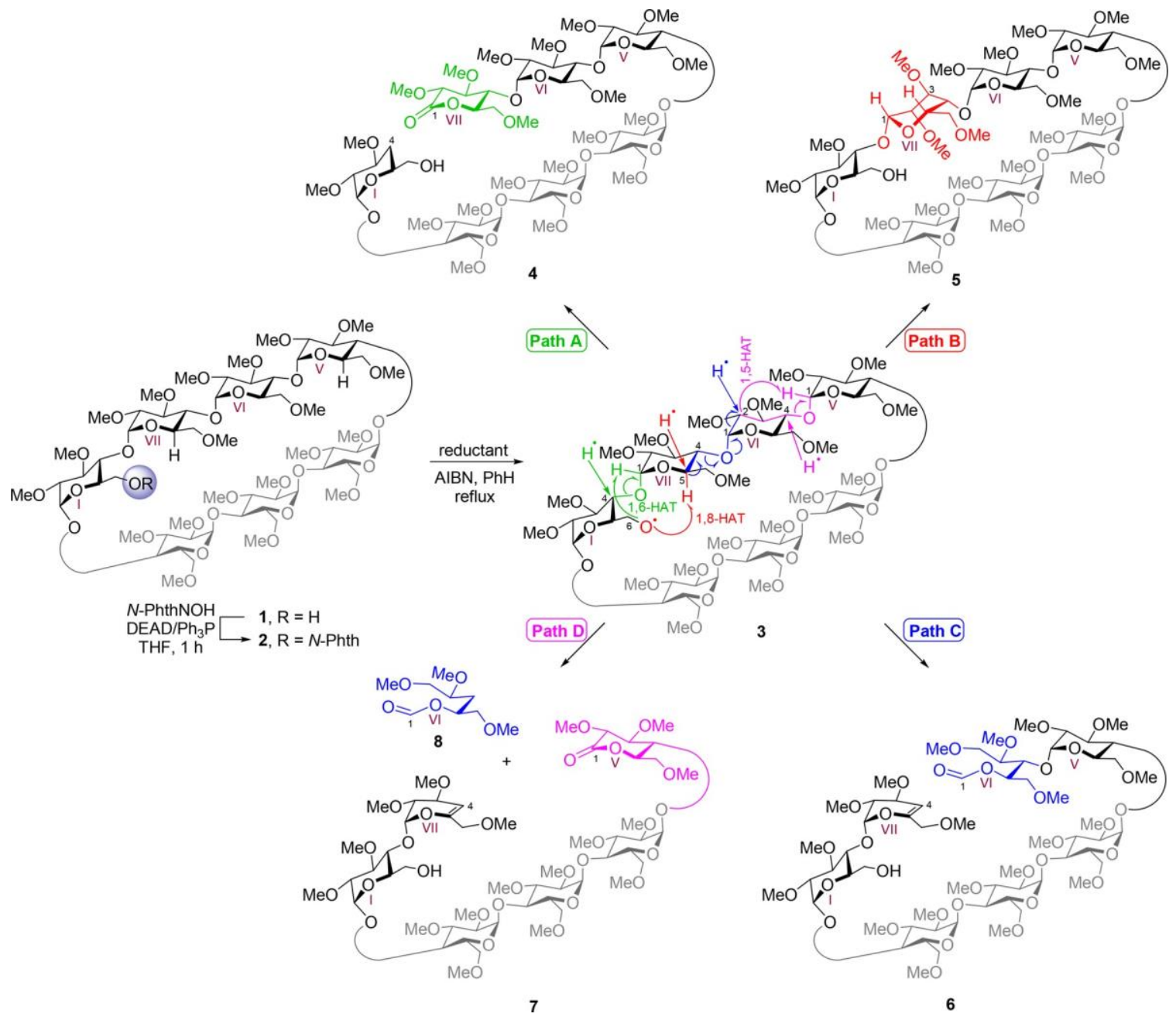

${ }^{a}$ Path $\mathrm{A}=1,6-\mathrm{HAT}\left(6^{\mathrm{I}} \mathrm{O}^{\bullet} \rightarrow 1^{\mathrm{VII}} \mathrm{C}^{\bullet}\right)-\beta-\mathrm{Fra}\left(1^{\mathrm{VII}} \mathrm{C}^{\bullet} \rightarrow 4^{\mathrm{I}} \mathrm{C}^{\bullet}\right)+\mathrm{H}^{\bullet}$, path B $=1,8-\mathrm{HAT}\left(6^{\mathrm{I}} \mathrm{O}^{\bullet} \rightarrow 5^{\mathrm{VII}} \mathrm{C}^{\bullet}\right)+\mathrm{H}^{\bullet}$, path $\mathrm{C}=1,8-\mathrm{HAT}\left(6^{\mathrm{I}} \mathrm{O}^{\bullet} \rightarrow 5^{\mathrm{VII}} \mathrm{C}^{\bullet}\right)-\beta-$ $\mathrm{Fra}\left(5^{\mathrm{VII}} \mathrm{C}^{\bullet} \rightarrow 1^{\mathrm{VI}} \mathrm{O}^{\bullet}\right)-\beta-\mathrm{Fra}\left(1^{\mathrm{VI}} \mathrm{O}^{\bullet} \rightarrow 2^{\mathrm{VI}} \mathrm{C}^{\bullet}\right)+\mathrm{H}^{\bullet}$, path $\mathrm{D}=1,8-\mathrm{HAT}\left(6^{\mathrm{I}} \mathrm{O}^{\bullet} \rightarrow 5^{\mathrm{VII}} \mathrm{C}^{\bullet}\right)-\beta-\mathrm{Fra}\left(5^{\mathrm{VII}} \mathrm{C}^{\bullet} \rightarrow 1^{\mathrm{VI}} \mathrm{O}^{\bullet}\right)-\beta-F r a\left(1^{\mathrm{VI}} \mathrm{O}^{\bullet} \rightarrow 2^{\mathrm{VI}} \mathrm{C}^{\bullet}\right)-1,5-\mathrm{HAT}-$ $\left(2^{\mathrm{VI}} \mathrm{C}^{\bullet} \rightarrow 1^{\mathrm{V}} \mathrm{C}^{\bullet}\right)-\beta-\mathrm{Fra}\left(1^{\mathrm{V}} \mathrm{C}^{\bullet} \rightarrow 4^{\mathrm{VI}} \mathrm{C}^{\bullet}\right)+\mathrm{H}^{\bullet}$. Small quantities $(9-17 \%)$ of reduced alcohol 1 were also obtained with all reducing agents (see Table 1). $N$-PhthNOH $=N$-hydroxyphthalimide.

fate of $2^{\mathrm{I}-\mathrm{VII}}, 3^{\mathrm{I}-\mathrm{VII}}, 6^{\mathrm{II}-\mathrm{VII}}$-icosa- $O$-methyl- $\beta$-cyclomaltoheptaos$6^{\mathrm{I}}-\mathrm{O}$-yl radical (3) under reductive conditions.

The starting $2^{\mathrm{I}-\mathrm{VII}}, 3^{\mathrm{I}-\mathrm{VII}}, 6^{\mathrm{II}-\mathrm{VII}}$-icosa-O-methyl-6- $\mathrm{I}-\mathrm{O}$-phthalimidyl- $\beta$-cyclomaltoheptaose (2) was prepared from the corresponding known alcohol $1^{2}$ and $N$-hydroxyphthalimide using Mitsunobu conditions (see Scheme 2). ${ }^{10}$ Treatment of phthalimide 2 with $n-\mathrm{Bu}_{3} \mathrm{SnH} / \mathrm{AIBN}^{11}$ afforded the $6^{\mathrm{I}}-\mathrm{O}-\mathrm{yl}$ radical 3 that triggered a cascade sequence giving rise to five compounds (see entry 2 in Table 1 (presented later in this work), global yield $=86 \%$ ), four constitutional isomers $(1,4,5$, and 6) and one acyclic hexasaccharide (7), from which a sugar unit has been lost. From the structure of these compounds, a clear picture of the involved mechanism should emerge.

The ${ }^{1} \mathrm{H}$ NMR spectrum of compound 4 showed the disappearance of one of the seven anomeric protons, and clearly, the formation of a D-glucono-1,5-lactone residue, suggesting an acyclic heptasaccharide structure formed by the $4^{\mathrm{I}} \mathrm{C}-1^{\mathrm{VII}} \mathrm{O}$ bond cleavage. The appearance of two high-field signals attributable to the axial $[1.35 \mathrm{ppm}$ (ddd, $J=12.3,12.3$, $12.3 \mathrm{~Hz})]$ and equatorial $[2.03 \mathrm{ppm}(\mathrm{ddd}, J=12.6,4.7,2.2$ $\mathrm{Hz})$ ] protons at $4^{\mathrm{I}} \mathrm{C}$ confirm the proposed structure. The formation of this minor product may be considered formally an intramolecular two-electron neutral-redox fragmentation and can be schematically represented as a three-step radical process: $1,6-\mathrm{HAT}\left(6^{\mathrm{I}} \mathrm{O}^{\bullet} \rightarrow 1^{\mathrm{VII}} \mathrm{C}^{\bullet}\right)-\beta-\mathrm{Fra}\left(1^{\mathrm{VII}} \mathrm{C}^{\bullet} \rightarrow 4^{\mathrm{I}} \mathrm{C}^{\bullet}\right)+\mathrm{H}^{\bullet}$ (path A). The reaction is initiated from a 1,6-HAT of the $1^{\mathrm{VII}} \mathrm{H}$ anomeric proton by the 6 - $-O$-yl radical, followed by a $\beta$-fragmentation of the aglyconic $4^{\mathrm{I}} \mathrm{C}-1^{\mathrm{VII}} \mathrm{O}$ bond and subsequent quenching of the $4^{\mathrm{I}} \mathrm{C}$ radical by the reagent.

Two other minor products resulted directly from the 1,8$\mathrm{HAT}\left(6^{\mathrm{I}} \mathrm{O}^{\bullet} \rightarrow 5^{\mathrm{VII}} \mathrm{C}^{\bullet}\right)+\mathrm{H}^{\bullet}$ reaction (path $\mathrm{B}$ ): the alcohol 5 $(18 \%)$, formed by hydrogen abstraction at $5^{\mathrm{VII}} \mathrm{C}$ and subsequent radical quenching with inversion of configuration, and starting alcohol 1 (17\%), which could arise either by abstraction and retention of the configuration at $5^{\mathrm{VII}} \mathrm{C}$ or simply by reduction of the 6 I-O -yl radical prior to the abstraction or very probably by a combination of both mechanisms. Alcohol 5 possesses a cyclic structure in which the $\alpha$-D-Glc $p$ VII-unit has been transformed to $\beta$-L-Idop. In consequence, the typical ${ }^{4} C_{1}$ chair conformation of the D-Glc $p$ ring has changed to ${ }^{1} C_{4}$, preferential feature of the L-sugars. This is evident in its ${ }^{1} \mathrm{H}$ NMR spectrum, the coupling constant of $1^{\mathrm{VII}} \mathrm{H}\left[{ }^{3} J_{1,2}=1.6 \mathrm{~Hz}\right.$ 
(calcd $1.1 \mathrm{~Hz}$ )] being significantly smaller than the values of the coupling constants $\left({ }^{3} J_{1,2} \approx 3.5 \mathrm{~Hz}\right)$ for the other anomeric protons of the $\boldsymbol{\alpha}$-D-Glc $p$ rings (see Figure S1 in the Supporting Information (SI)). The downfield-shifted $3^{\mathrm{VII}} \mathrm{H}$ signal also disclosed a similarly small ${ }^{1} C_{4}$ ring coupling for ${ }^{3} J_{2,3} \approx{ }^{3} J_{3,4}=2.8$ $\mathrm{Hz}$ (calcd 2.9 and $3.0 \mathrm{~Hz}$, respectively). As far as we know, such $\beta$-CD with a structure of cyclo[4)-2,3-di-O-methyl- $\alpha-\mathrm{D}-\mathrm{Glc} p$ $(1 \rightarrow 4)$-[2,3,6-tri-O-methyl- $\boldsymbol{\alpha}$-D-Glc $p$ - $(1 \rightarrow 4)]_{5}$-2,3,6-tri-Omethyl- $\beta$-L-Ido $p-(1 \rightarrow]$ (5) has never been prepared.

Considerable spectroscopic data were diagnostic of the 4deoxy-2,3,6-tri- $O$-methyl- $\beta$-L-threo-hex-4-enopyranoside (VIIunit) and 4-O-formyl-1,2,5-tri-O-methyl-D-arabinitol (VI-unit) terminal residues present in the acyclic structure of heptasaccharide 6. In a minimized structure of a model compound (see Figure S2 in the SI), the hex-4-enopyranose ring adopts preferentially a ${ }^{2} H_{1}$ half-chair conformation, from which the calculated coupling constants agree well with the experimental values $\left[3_{1,2}=2.5 \mathrm{~Hz}(\right.$ calcd $2.7 \mathrm{~Hz}) ;{ }^{3} J_{3,4}=2.8 \mathrm{~Hz}$ (calcd $2.0 \mathrm{~Hz}$ )]. As can be observed, the original $1^{\mathrm{VI}}$-anomeric carbon in the starting D-Glc $p$ VI-unit has been transformed into the formate group, appearing to indicate two consecutive $\beta$ fragmentation reactions. The $5^{\mathrm{VII}} \mathrm{C}^{\bullet}$ radical generated by the 1,8-HAT reaction is stabilized through a fragmentation of the $4^{\mathrm{VII}} \mathrm{C}-1^{\mathrm{VI}} \mathrm{O}$ bond to give rise to the $4^{\mathrm{VII}} \mathrm{C}-5^{\mathrm{VII}} \mathrm{C}$ double bond and a $1^{\mathrm{VI}}-\mathrm{O}$-yl radical. This new alkoxyl radical again undergoes rapid $\beta$-scission to form the formate group and a secondary $2^{\mathrm{VI}} \mathrm{C}^{\bullet}$ radical which is trapped by the $n-\mathrm{Bu}_{3} \mathrm{SnH} \cdot \underline{12}$ Accordingly, the formation of 6 proceeds through a four-step sequence: 1,8 $\mathrm{HAT}\left(6^{\mathrm{I}} \mathrm{O}^{\bullet} \rightarrow 5^{\mathrm{VII}} \mathrm{C}^{\bullet}\right)-\beta-\mathrm{Fra}\left(5^{\mathrm{VII}} \mathrm{C}^{\bullet} \rightarrow 1^{\mathrm{VI}} \mathrm{O}^{\bullet}\right)-\beta-\mathrm{Fra}\left(1^{\mathrm{VI}} \mathrm{O}^{\bullet} \rightarrow\right.$ $\left.2^{\mathrm{VI}} \mathrm{C}^{\bullet}\right)+\mathrm{H}^{\bullet}$ (path $\left.\mathrm{C}\right)$.

Compound 7 is an acyclic hexasaccharide with two clearly distinguishable terminal residues: 4-deoxy-2,3,6-tri- $O$-methyl- $\beta$ L-threo-hex-4-enopyranoside (VII-unit) and 2,3,6-tri- $\mathrm{O}$-methylD-glucono-1,5-lactone (V-unit). The VI-unit has been lost as 3deoxy-2-O-formyl-1,4,5-tri-O-methyl-D-threo-pentitol (8), its chemical composition $\left(\mathrm{C}_{9} \mathrm{H}_{18} \mathrm{O}_{5}\right)$ accounting for the difference between the molecular formulas of 6 and 7 . Compound 8 can be detected in the ${ }^{1} \mathrm{H}$ NMR spectrum of the crude reaction mixture and isolated on the less-polar fractions of the chromatography, being identical with a synthetic sample upon

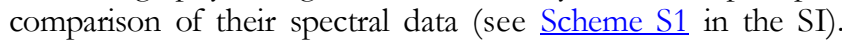
The purification and identification step is better accomplished in an experiment using (TMS) $)_{3} \mathrm{SiH}$ as reductant, where it is formed in higher proportion (see entry 3 in Table 1 (presented later in this work)) (vide infra).

The transformation of the D-Glcp V-unit into a D-glucono1,5-lactone residue, as in the case of compound 4 , seems to imply a $1,5-\mathrm{HAT}$ of the $1^{\mathrm{V}} \mathrm{H}$ by the previously formed $2^{\mathrm{VI}} \mathrm{C}^{\bullet}$ radical, followed by a $\beta$-fragmentation of the $4{ }^{\mathrm{VI}} \mathrm{C}-1^{\mathrm{V}} \mathrm{O}$ bond, which releases the VI-unit. Therefore, the mechanism of formation of compound 7 would entail six steps through the following sequence: $1,8-\mathrm{HAT}\left(6^{\mathrm{I}} \mathrm{O}^{\bullet} \rightarrow 5^{\mathrm{VII}} \mathrm{C}^{\bullet}\right)-\beta$-Fra $\left(5^{\mathrm{VII}} \mathrm{C}^{\bullet} \rightarrow\right.$ $\left.1^{\mathrm{VI}} \mathrm{O}^{\bullet}\right)-\beta-F r a\left(1^{\mathrm{VI}} \mathrm{O}^{\bullet} \rightarrow 2^{\mathrm{VI}} \mathrm{C}^{\bullet}\right)-1,5-\mathrm{HAT}\left(2^{\mathrm{VI}} \mathrm{C}^{\bullet} \rightarrow 1^{\mathrm{V}} \mathrm{C}^{\bullet}\right)-\beta$ $\operatorname{Fra}\left(1^{\mathrm{V}} \mathrm{C}^{\bullet} \rightarrow 4^{\mathrm{VI}} \mathrm{C}^{\bullet}\right)+\mathrm{H}^{\bullet}$ (path D).

Acid-catalyzed hydrolysis of compound 7 afforded the pentasaccharide 9 with loss of the hex-4-enopyranoside residue as the $\delta$-keto-aldehyde 10 (see Scheme 3 ). Compound 10 was somewhat unstable and could not be purified satisfactorily, because of decomposition during chromatography over silica, but was spectroscopically compared with an authentic sample prepared by synthesis (see Scheme S2 in the SI).

Despite the poor selectivity and low yields obtained, this approach holds great promise for realizing in a single step $\beta-C D$

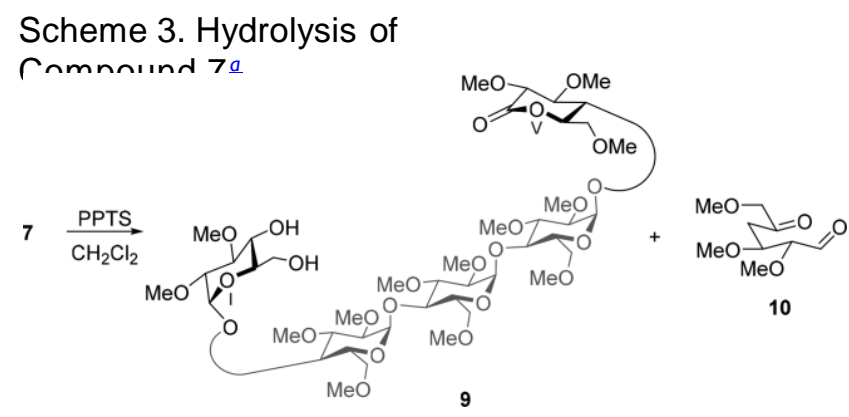

${ }^{a}$ PPTS $=$ pyridinium $p$-toluenesulfonate.

transformations very difficult to achieve by other methods. Mainly, the change of an $\alpha$-D-Glc $p$ residue into $\beta$-L-Idop with the predictable modifications of the cavity size and/or shape, which may alter the original inclusion ability. The selective opening of the cyclic skeleton of this readily accessible substrate to produce heptasaccharides, hexasaccharides, and pentasaccharides with different terminal residues may also have interesting synthetic applications. For example, pentasaccharide 9 may be useful in the synthesis of small ring CDs cyclo[4)- $\alpha$ -

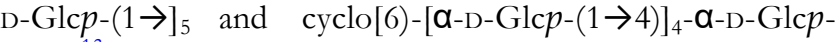
$(1 \rightarrow] . \underline{13}$

With all these considerations in mind, we decided to explore the role played by the nature of the reductant in the modulation of the selectivity. The reactivity of phthalimide 2 over various group 14 hydrides is shown in Table $1 .{ }^{18}$ Hydrogen donor abilities of these hydrides have been extensively studied and the rate constants for reaction with the $t$ - $\mathrm{BuO}^{\bullet}$ radical are listed in the table for comparative purposes. ${ }^{19} \mathrm{Ph}_{3} \mathrm{SnH}$, which is a better hydrogen donor than $n-\mathrm{Bu}_{3} \mathrm{SnH}$, stop the radical sequence at the beginning, immediately after the 1,8-HAT reaction, providing 5 very predominantly in a satisfactory yield $(61 \%$; Table 1 , entry 1). A small amount of compound 6 is also formed $(7 \%)$, but the radical cannot complete the sequence and compound 7 was not detected. In contrast, when the lessreactive (TMS ${ }_{3} \mathrm{SiH}^{20}$ is used, the radical can reach the end of the sequence and compound 7 is formed preferentially (49\%; Table 1, entry 3). The intermediate compound 6 (13\%) can also be obtained, but the reagent cannot trap the radical as it passes through $5^{\mathrm{VII}} \mathrm{C}$ and compound 5 is not formed. When $n$ $\mathrm{Bu}_{3} \mathrm{GeH}$, a reagent with analogous reactivity to (TMS) ${ }_{3} \mathrm{SiH}$ was used, very similar results were obtained, albeit with poorer yields (Table 1, entry 4). $\underline{21}$ The aforementioned results obtained with $n$ - $\mathrm{Bu}_{3} \mathrm{SnH}$ can now be reasonably explained: a reagent of average reactivity should give preferentially the intermediate 6 combined with a mixture of all possible products (Table 1, entry 2).

In summary, the fate of the $6^{\mathrm{I}}-\mathrm{O}$-yl radical moves through the saccharide skeleton by two different cascadereactions:

(i) Cascade A is initiated by 1,6-HAT of the anomeric hydrogen at $1^{\mathrm{VII}} \mathrm{C}$ and gives exclusively heptasaccharide 4 (path A). This is a very minor process that is practically independent of the hydrogen donor capacities of the hydrides and must be dependent mainly on the energy of the seven-membered transition state involved (see Table 1). As commented previously, a process of this type has never been observed in the analogous methyl $\beta$-maltoside disaccharide.

(ii) Cascade $\mathrm{B}$ is triggered by $1,8-\mathrm{HAT}$ of the hydrogen at $5^{\mathrm{VII}} \mathrm{C}$ and the radical can reach the anomeric hydrogen at $1^{\mathrm{V}} \mathrm{C}$ three sugar units ahead, only by HAT and $\beta$-fragmentation processes. The $1^{\mathrm{V}} \mathrm{C}$ radical is subsequently stabilized by $\beta$ - 
Table 1. Reactivity of Phthalimide 2 over Various Group 14

\begin{tabular}{|c|c|c|c|c|c|c|c|c|c|}
\hline \multirow[b]{2}{*}{ entry } & \multirow[b]{2}{*}{ reductant } & \multirow[b]{2}{*}{ ref } & \multirow[b]{2}{*}{$k^{\underline{a}}\left(\times 10^{-8} \mathrm{dm}^{3} \mathrm{~mol}^{-1} \mathrm{~s}^{-1}\right)$} & \multicolumn{4}{|c|}{ Yield $(\%)$} & & \multirow[b]{2}{*}{ total yield $(\%)$} \\
\hline & & & & 1 & 4 & 5 & 6 & 7 & \\
\hline 1 & $\mathrm{Ph}_{3} \mathrm{SnH}$ & $\underline{14}$ & 4.3 & 13 & 3 & 61 & 7 & & 84 \\
\hline 2 & $n-\mathrm{Bu}_{3} \mathrm{SnH}$ & $\underline{15}$ & 1.9 & 17 & 5 & 18 & 42 & 4 & 86 \\
\hline 3 & $(\mathrm{TMS})_{3} \mathrm{SiH}$ & $\underline{16}$ & 1.1 & 12 & 3 & & 13 & 49 & 77 \\
\hline 4 & $n-\mathrm{Bu}_{3} \mathrm{GeH}$ & $\underline{17}$ & 0.9 & 9 & 4 & & 12 & 37 & 62 \\
\hline
\end{tabular}

${ }^{a}$ Absolute rate constants for reaction of group 14 hydrides with the tert-butoxyl radical $(t$-BuO') at room temperature (rt).

fragmentation of the $1{ }^{\mathrm{V}} \mathrm{O}-4^{\mathrm{VI}} \mathrm{C}$ bond to give finally compound 7 (path D).

Note that both cascades ended via the same mechanism: $1, n$ HAT of an anomeric proton and $\beta$-fragmentation of the adjacent aglyconic $1^{n} \mathrm{O}-4^{n+1} \mathrm{C}$ bond. Interestingly, in this last cascade, we can modify the selectivity of the reaction through a judicious choice of the reductant and compounds 5-7 can be conveniently prepared in reasonable yields. To our knowledge, this represents the largest number of steps ever observed in a radical cascade without the intervention of unsaturated bonds. We believe that these results may shed light on the mechanism of radical reactions in $(1 \rightarrow 4)$-linked oligosaccharides that are present in biological systems, $\stackrel{22}{2}$ and could also be useful in structural characterization of oligosaccharides via the radical directed dissociation technique in tandem mass spectrometry. $\frac{23}{}$

\section{ASSOCIATED}

\section{* suppepdrtefintinformation}

The Supporting Information is available free of charge on the ACS Publications website at DOI: $10.1021 /$ acs.orglett. $8 \mathrm{~b} 01308$.

Experimental procedures, characterization data, and NMR spectra for all products $(\underline{\mathrm{PDF}})$

\section{AUTHOR}

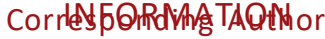

*E-mail: angelesmartin@ipna.csic.es.

\section{ORCID}

\section{Angeles Martín: $\underline{0000-0001-5524-4828}$}

Notes

The authors declare no competing financial interest.

\section{ACKNOWLEDGMENT}

Finaf cial support by the Investigation Programs of the Ministerio de Economiay Competitividad (No. CTQ201018244), FundacionCajaCanarias (No. 2015-BIO08) and the Gobierno de Canarias (No. ProID2017010017) is acknowledged.

\section{REFERENCES}

(1) (a) Hung, K.; Hu, X.; Maimone, T. J. Nat. Prod. Rep. 2018, 35, 174-202. (b) Plesniak, M. P.; Huang, H.-M.; Procter, D. J. Nat. Rev. Chem. 2017, 1, 0077. (c) Yan, M.; Lo, J. C.; Edwards, J. T.; Baran, P. S. J. Am. Chem. Soc. 2016, 138, 12692-12714. (d) Ardkhean, R.; Caputo,

D. F. J.; Morrow, S. M.; Shi, H.; Xiong, Y.; Anderson, E. A. Chem. Soc. Rev. 2016, 45, 1557-1569. (e) Baralle, A.; Baroudi, A.; Daniel, M.;

Fensterbank, L.; Goddard, J.-P.; Lacôte, E.; Larraufie, M.-H.; Maestri, G.; Malacria, M.; Ollivier, C. In Encyclopedia of Radicals in Chemistry,

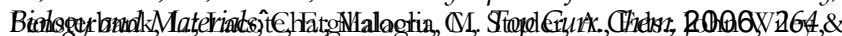
Sons: Chichester, U.K., 2012; Vol. 2, pp 729-766. (f) Albert, M.;
1-62. (g) Nicolaou, K. C.; Edmonds, D. J.; Bulger, P. G. Angew. Chem., Int. Ed.2006, 45, 7134-7186.

(2) (a) Cekovic,Z̈; Ilijev, D. Tetrahedron Lett. 1988, 29, 1441-1444. (b) Rawal, V. H.; Newton, R. C.; Krishnamurthy, V. J. Org. Chem. 1990, 55, 5181-5183. (c) Rawal, V. H.; Krishnamurthy, V. Tetrahedron Lett. 1992, 33, 3439-3442. (d) Moman, E.; Nicoletti, D.; Mouriño, A. Org. Lett. 2006, 8, 1249-1251. (e) Zhu, H.; Wickenden, J. G.; Campbell, N. E.; Leung, J. C. T.; Johnson, K. M.; Sammis, G. M. Org. Lett. 2009, 11, 2019-2022.

(3) (a) Goto, M.; Miyoshi, I.; Ishii, Y.; Ogasawara, Y.; Kakimoto, Y.I.; Nagumo, S.; Nishida, A.; Kawahara, N.; Nishida, M. Tetrahedron 2002, 58, 2339-2350. (b) Chuard, R.; Giraud, A.; Renaud, P. Angew. Chem., Int. Ed. 2002, 41, 4321-4323. (c) Chuard, R.; Giraud, A.;

Renaud, P. Angew. Chem., Int. Ed. 2002, 41, 4323-4325. (d) BookerMilburn, K. I.; Dainty, R. F. Tetrahedron Lett. 1998, 39, 5097-5100. For a cascade initiated by alkoxyl radical $\beta$-fragmentation, see: (e) Mowbray, C. E.; Pattenden, G. Tetrahedron Lett. 1993, 34, 127130.

(4) (a) Francisco, C. G.; Herrera, A. J.; Kennedy, A. R.; Melian, D.; Suarez, E. Angew. Chem., Int. Ed. 2002, 41, 856-858. (b) Francisco, C. G.; Herrera, A. J.; Kennedy, A. R.; Martín, A.; Melian, D.; Pérez- Martín, I.; Quintanal, L. M.; Suarez, E. Chem.- Eur.J. 2008, 14, 10369- 10381. (5)For a recent review on HAT reactions, see Nechab, M.; Mondal, S.; Bertrand, M. P. Chem.- Eur. J.2014, 20,16034-16059.

(6) (a) Alvarez-Dorta, D.; Leon, E. I.; Kennedy, A. R.; Martín, A.; Perez-Martín, I.; Suarez, E. Angew. Chem., Int. Ed. 2015, 54, 36743678. (b) Alvarez-Dorta, D.; Leon, E. I.; Kennedy, A. R.; Martín, A.; Perez-Martín, I.; Suarez, E. J. Org. Chem. 2016, 81, 11766-11787.

(7) For a review, see: (a) Gattuso, G.; Nepogodiev, S. A.; Stoddart, J. F. Chem. Rev. 1998, 98, 1919-1958. For the synthesis of cyclo[4)- $\boldsymbol{\alpha}$-LRhap- $(1 \rightarrow]_{6}$ and cyclo[4)- $\boldsymbol{\alpha}-\mathrm{L}-\mathrm{Rhap}-(1 \rightarrow]_{5}$, see: (b) Nishizawa, M.; Imagawa, H.; Kan, Y.; Yamada, H. Tetrahedron Lett. 1991, 32, 55515554. (c) Nishizawa, M.; Imagawa, H.; Kubo, K.; Kan, Y.; Yamada, H. Synlett 1992, 1992, 447-448. (d) Nishizawa, M.; Imagawa, H.; Morikuni, E.; Hatakeyama, S.; Yamada, H. Chem. Pharm. Bull. 1994, 42, 1365-1366. For the synthesis of cyclo[4)- $\alpha-\mathrm{L}-\mathrm{Rhap}-(1 \rightarrow 4)-\mathbf{\alpha}-\mathrm{D}-$ $\operatorname{Man} p-(1 \rightarrow]_{3}$ and cyclo[4)- $\boldsymbol{\alpha}_{-\mathrm{L}-\mathrm{Rhap}}-(1 \rightarrow 4)-\boldsymbol{\alpha}$-D-Man $p-(1 \rightarrow]_{4}$, see: (e) Ashton, P. R.; Brown, C. L.; Menzer, S.; Nepogodiev, S. A.; Stoddart, J. F.; Williams, D. J. Chem. - Eur. J. 1996, 2, 580-591. For the synthesis of achiral CDs with alternating D- and L- residues, see: (f) Ashton, P. R.; Cantrill, S. J.; Gattuso, G.; Menzer, S.; Nepogodiev, S. A.; Shipway, A. N.; Stoddart, J. F.; Williams, D. J. Chem.- Eur. J. 1997, 3, 1299-1314.

(8) For recent examples on modified cyclodextrins, see: (a) GarcíaMoreno, M. I.; de la Mata, M.; Sanchez-Fernandez, E. M.; Benito, J. M.; Díaz-Quintana, A.; Fustero, S.; Nanba, E.; Higaki, K.; Sanchez- Alcazar, J. A.; García Fernandez, J. M.; Ortiz Mellet, C. J. Med. Chem. 2017, 60, 1829-1842. (b) Fujita, K.; Fujiwara, S.; Yamada, T.; Tsuchido, Y.; Hashimoto, T.; Hayashita, T. J. Org. Chem. 2017, 82, 976-981. (c) Huang, X.; Yasunaga, S.; Fukudome, M.; Chen, W.-H.; Yuan, D.-Q. Org. Biomol. Chem. 2017, 15, 4077-4080. (d) Volkov, S.; Kumprecht, L.; Budešnsky,M.; Lepsǐk, M.; Dusek, M.; Kraus, T. Org. Biomol. Chem. 2015, 13, 2980-2985. (e) Chmurski, K.; Stepniak, P.; Jurczak, J. Synthesis 2015, 47, 1838-1843. (f) Menuel, S.; Doumert, B.; Saitzek, S.; Ponchel, A.; Delevoye, L.; Monflier, E.; Hapiot, F. J; Org. Chem. 2015, 80, 6259-6266. (g) Gallego-Yerga, L.; Gonzalez-Alvarez,

M. J.; Mayordomo, N.; Santoyo-Gonzalez, F.; Benito, J. M.; Ortiz 
Mellet, C.; Mendicuti, F.; García Fernandez, J. M. Chem.- Eur. J. 2014, 20, 6622-6627. (h) Rodríguez-Lavado, J.; de la Mata, M.; JimenezBlanco, J. L.; García-Moreno, M. I.; Benito, J. M.; Díaz-Quintana, A.; Sanchez-Alcazar, J. A.; Higaki, K.; Nanba, E.; Ohno, K.; Suzuki, Y.; Ortiz Mellet, C.; García Fernandez, J. M. Org. Biomol. Chem. 2014, 12, 2289-2301. (i) Gu, J.; Chen, T.; Zhang, P.; Ling, C.-C. Eur.J. Org. Chem. 2014, 2014, 5793-5805. (j) Wang, B.; Zaborova, E.; Guieu, S.; Petrillo, M.; Guitet, M.; Blériot, Y.; Menand, M.; Zhang, Y.; Sollogoub, M. Nat. Commun.2014, 5, 5354. For a review, see: (k) Rezanka, M. Eur. J. Org. Chem. 2016, 2016, 5322-5334. For examples on the influence of conformational alterations in the complexing properties, see: (l) Neva, T.; Carmona, T.; Benito, J. M.; Przybylski, C.; Ortiz Mellet, C.; Mendicuti, F.; García Fernandez, J. M. J. Org. Chem. 2018, 10.1021/acs.joc.8b00602. (m) Meo, P. L.; D'Anna, F.; Riela, S.; Gruttadauria, M.; Noto, R. J. InclusiónPhenom. Chem. 2011, 71, 121-

127. (n) Yoshikiyo, K.; Matsui, Y.; Yamamoto, T.; Okabe, Y. Bull. Chem. Soc. Jpn. 2007, 80, 1124-1128.

(9) (a) Chen, Z.; Bradshaw, J. S.; Lee, M. L. Tetrahedron Lett. 1996,

37, 6831-6834. (b) Yi, G.; Bradshaw, J. S.; Rossiter, B. E.; Malik, A.; Li, W.; Petersson, P.; Markides, K. E.; Lee, M. L. J. Org. Chem. 1993, $58,4844-4850$.

(10) (a) Mitsunobu, O. Synthesis 1981, 1981, 1-28. (b) Grochowski, E.; Jurczak, J. Synthesis 1976, 1976, 682-684.

(11) For early reports on the use of $n-\mathrm{Bu}_{3} \mathrm{SnH}$ for the generation of alkoxyl radicals from $N$-alkoxyphthalimides, see: (a) Kim, S.; Lee, T. A.; Song, Y. Synlett 1998, 1998, 471-472. (b) Okada, K.; Okamoto, K.; Oda, M. J. Am. Chem. Soc. 1988, 110, 8736-8738. (c) Martín, A.; Rodríguez, M. S.; Suarez, E. Tetrahedron Lett. 1999, 40, 7525-7528.

(12)For the $\beta$-fragmentation kinetics of alkoxyl radicals, see Beckwith, A. L. J.; Hay, B. P. J. Am. Chem. Soc. 1989, 111, 230-234.

(13) (a) Nakagawa, T.; Ueno, K.; Kashiwa, M.; Watanabe, J.

Tetrahedron Lett. 1994, 35, 1921-1924. (b) Immel, S.; Brickmann, J.; Lichtenthaler, F. W. Liebigs Ann. 1995, 1995, 929-942. See also ref $\underline{7 \mathrm{a}}$.

(14)Chatgilialoglu, C.; Ingold, K. U.; Lusztyk, J.; Nazran, A. S.; Scaiano, J. C. Organometallics 1983, 2, 1332-1335.

(15) Scaiano, J. C. J. Am. Chem. Soc. 1980, 102, 5399-5400.

(16)Chatgilialoglu, C.; Rossini, S. Bull. Soc. Chim. Fr. 1988, 298- 300.

(17) Chatgilialoglu, C.; Scaiano, J. C.; Ingold, K. U. Organometallics

1982, 1, 466-469.

(18)As far as we know, $n-\mathrm{Bu}_{3} \mathrm{GeH}$ has never been used for the generation of alkoxyl radicals from $N$-alkoxyphthalimides. For the use of (TMS) ${ }_{3} \mathrm{SiH}$ in this regard, see: (a) Hernandez-García, L.; Quintero, L.; Sanchez, M.; Sartillo-Piscil, F. J. Org. Chem. 2007, 72,8196-8201.

(b) Zlotorzynska, M.; Zhai, H.; Sammis, G. M. Org. Lett. 2008, 10, 5083-5086. See also ref 11a. For the use of $\mathrm{Ph}_{3} \mathrm{SnH}$, see ref2e.

(19) Chatgilialoglu, C.; Newcomb, M. Adv. Organomet. Chem. 1999, $44,67-112$.

(20) (a) Ballestri, M.; Chatgilialoglu, C.; Clark, K. B.; Griller, D.; Giese, B.; Kopping, B. J. Org. Chem. 1991, 56, 678-683. For reviews, see: (b) Chatgilialoglu, C.; Timokhin, V. I. In Encyclopedia of Radicals in Chemistry, Biology and Materials; Chatgilialoglu, C., Studer, A., Eds.; John Wiley \& Sons: Chichester, U.K., 2012; Vol. 2, pp 561-600.

(c) Chatgilialoglu, C.; Timokhin, V. I. Adv. Organomet. Chem. 2008, 57, 117-181. (d) Chatgilialoglu, C. Chem. - Eur. J. 2008, 14, 23102320. (e) Chatgilialoglu, C. Organosilanes in Radical Chemistry; John Wiley \& Sons: Chichester, U.K., 2004. (f) Chatgilialoglu, C. In Radicals in Organic Synthesis; Renaud, P., Sibi, M. P., Eds.; WileyVCH: Weinheim, Germany, 2001; Vol. 1, pp 28-47. (g) Chatgilialoglu, C. Chem. Rev. 1995, 95, 1229-1251. (h) Chatgilialoglu, C. Acc. Chem. Res. 1992, 25, 188-194.

(21)Bowman, W. R.; Krintel, S. L.; Schilling, M. B. Org. Biomol. Chem. 2004, 2, 585-592.

(22) For radical reaction reviews on biological systems, see: Encyclopedia of Radicals in Chemistry, Biology and Materials, Vol. 3; Chatgilialoglu, C., Studer, A., Eds.; John Wiley \& Sons: Chichester, U.K., 2012.

(23) Zhang, X.; Julian, R. R. Int. J. Mass Spectrom. 2014, 372, 22-28. 